\title{
INOVAÇÃO E PRODUÇÃo NA QUÍMICA FINA
}

\author{
Nelson Brasil de Oliveira
}

Associação Brasileira das Indústrias de Química Fina, Biotecnologia e suas Especialidades. Av. Churchill, 129, conj. 1003, 20020-050 Rio de Janeiro - RJ

\begin{abstract}
FINE CHEMISTRY INNOVATION AND PRODUCTION. This paper makes a description of the fine chemistry industrial sector together with historical data on fine chemicals R\&D and production in Brazil, from the 70's to the present. Circumstances and factors for production growth in the 80's followed by sectorial shrinking in the 90's are critically examined as well as the current circumstances. An account is given on the fine chemistry industry in the world, considering the globalization, contract, technical trade barriers, competitivity and biotechnology issues. Key current questions in the Brazilian perspective are presented: technical capacity, regional and public policies as well as the verticalization of the industry.
\end{abstract}

Keywords: fine chemistry; chemical innovation and production; public and regional policies.

\section{INTRODUÇÃO}

O complexo industrial da química fina cobre uma extensa variedade de produtos químicos, com diferentes graus de pureza, que são denominados intermediários de síntese - posto que formam o elo entre a química de base e a química fina, bem como os intermediários de uso ou de performance (princípios ativos) e as formulações, misturas ou composições contendo tais produtos.

Os intermediários químicos de síntese são fabricados através de sínteses químicas ou, mais modernamente, via processos biotecnológicos a partir de matérias-primas da química orgânica básica, seja de origem petroquímica, seja da biomassa. De tais intermediários de síntese são produzidos os intermediários de uso.

As especialidades da química fina podem ser monodrogas ou misturas físicas sofisticadas, sempre se caracterizando pelo elevado conteúdo tecnológico incorporado e por se destinar a atender mercado final de produtos com grande valor unitário. Esse conceito é, modernamente, utilizado em todo o mundo, e surgiu inicialmente alinhado com uma concepção mais difundida na União Européia, diferentemente dos Estados Unidos - país em que os produtos da indústria química eram tratados de uma forma diferenciada das especialidades dela decorrentes.

O presente trabalho destina-se a divulgar entre profissionais da química, ou a empresários que desejam conhecer melhor o complexo industrial da química fina, conceitos que consideramos relevantes para a compreensão dos problemas do setor. Apresenta um breve histórico de sua evolução industrial no Brasil, mostra dados econômicos e de comércio relacionados aos produtos em questão, bem como alinha sugestões que vêm sendo defendidas pela Associação Brasileira das Indústrias de Química Fina (ABIFINA) com o objetivo de fundamentarem medidas de política industrial, tecnológica e de comércio exterior do governo federal, visando o desenvolvimento sustentado desse estratégico segmento da indústria química brasileira.

Esperamos que este trabalho sirva para um melhor entendimento do significado desse setor industrial no Brasil, em especial de sua importância estratégica para o soberano e sustentado crescimento do País.

*e-mail: diretoria@abifina.org.br

\section{A QUÍMICA FINA NO BRASIL}

\section{Abrangência do setor}

O complexo industrial da química fina compreende intermediários químicos de síntese, intermediários químicos de uso (ou princípios ativos utilizados para fabricação de especialidades - medicamentos e defensivos agrícolas ou animais) e as demais especialidades finais da química fina - produtos colocados no mercado consumidor. Os intermediários de síntese são moléculas químicas, geralmente orgânicas, que atendem aos requisitos químicos, físicos e físico-químicos (especificações técnicas) que constam de normas internacionais. Os intermediários de uso, além de obedecerem aos padrões internacionais (especificações técnicas), possuem características de aplicações típicas muito bem definidas, como a atividade biológica, pelo que são também conhecidos, na química fina, como intermediários químicos de performance. Intermediários inorgânicos de síntese química podem ser usados diretamente para obtenção de especialidades da química fina (alguns catalisadores e aditivos). No quadro I é apresentada essa concepção de cadeia produtiva para a química fina, da esquerda para a direita.

\section{Evolução inicial}

Ao longo do século XX, a química orgânica sofreu uma enorme evolução no mundo especialmente em decorrência da ampla disponibilidade de correntes gasosas e líquidas efluentes dos processos de refinação do petróleo cru, em substituição ao carvão que era muito utilizado para tais atividades, com destaque na Alemanha. A indústria petroquímica, que substituiu a indústria carboquímica, deu origem às diversas indústrias produtoras de resinas, fibras e fertilizantes, a custos bastante reduzidos, já que em grande parte era usado o gás de refino, cujo uso alternativo seria queimar no "flare" da refinaria.

Até o final dos anos 70 a indústria de química fina no Brasil era constituída por um reduzido número de empresas atuantes na área química ou de medicamentos - no último caso com clara inserção mercadológica e reduzido grau de verticalização da cadeia produtiva. Os primeiros laboratórios farmacêuticos nacionais foram fundados por empresários brasileiros inicialmente vinculados às áreas de vendas em laboratórios multinacionais. 
Quadro 1. Cadeias produtivas da química fina

\begin{tabular}{l|l|l|c}
\hline ORGÂNICOS & & $\begin{array}{l}\text { INTERMEDIÁRIOS DE USO } \\
\text { OU Detroquímica ou Biomassa } \\
\text { Fármacos ou Produtos Técnicos }\end{array}$ & MEDICAMENTOS \\
$\begin{array}{l}\text { INORGÂNICOS } \\
\text { Sintéticos ou Minerais Extrativos }\end{array}$ & INTERMEDIÁRIOS DE SÍNTESE & $\begin{array}{l}\text { ADITIVOS } \\
\text { CATALISADORES }\end{array}$ \\
\hline
\end{tabular}

Nos anos 70 foi desenvolvida, com pleno êxito, uma política industrial dedicada à montagem do grande parque petroquímico nacional, com a proteção do mercado interno para novos investimentos segundo o modelo tripartite de substituição de importações. Isso ocorria como decorrência de decisões do Conselho de Desenvolvimento Industrial (CDI) via Grupo de Estudos Setoriais da área química (GS-III), ao qual cabia aprovar projetos de investimentos, contando com a participação acionária da Petrobras (PETROQUISA, criada em 1967), o suporte financeiro do BNDES e a associação com empresas nacionais e estrangeiras - neste caso o "know how" sendo transferido pela multinacional.

\section{A explosão dos anos 80}

Com base no sucesso alcançado por essa política pública, ao longo dos anos 80 desenvolveu-se um grande programa de incentivo à industrialização na área de química fina, em especial após a edição da Portaria Interministerial $\mathrm{n}^{\circ} 04 / 84$. Através do uso do poder de compra do Estado - com destaque para a contratação de compras futuras em programas pluri-anuais pela Central de Medicamentos (CEME), pelo apoio ao desenvolvimento tecnológico - via CODETEC, e pelo financiamento para P\&D pela FINEP, e para projetos industriais via BNDES, foram promovidos investimentos que, entre 1984 e 1990, atingiram valores acumulados em torno de um bilhão de dólares. Nesse programa de química fina a PETROQUISA teve uma participação mais modesta do que naquele ocorrido com a petroquímica, sendo apenas associada indireta de alguns empreendimentos industriais vinculados à empresa "holding" NORQUISA.

\section{A queda dos anos 90}

Com a abertura comercial realizada pelo governo federal desde o início dos anos 90, sem prever qualquer período de adaptação à nova situação de mercado, segundo levantamento realizado pelo Ministério do Desenvolvimento, Indústria e Comércio Exterior, somente na área da química fina 1096 unidades produtivas foram fechadas no Brasil, bem como 355 projetos de desenvolvimento industrial foram cancelados, cujos números consolidados são apresentados na Tabela 1 .

Em período de forte apreciação cambial do real em relação ao dólar (1994-99), o resultado econômico da abertura comercial unilateral realizada pelo Brasil sobre o balanço do comércio externo brasileiro no contexto desse complexo industrial pode ser aferido pelo Gráfico 1, onde se verifica ainda uma retomada na aceleração desse déficit em 2004.

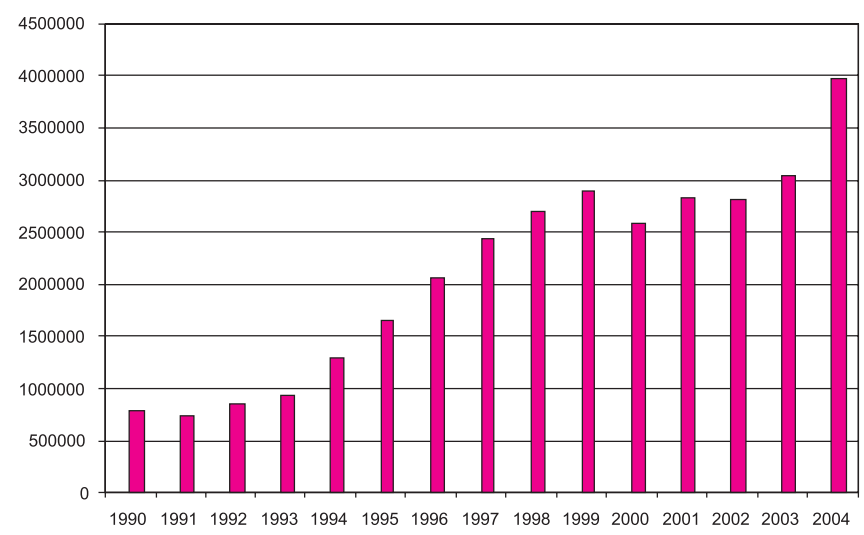

Gráfico 1. Déficit do balanço comercial da Química Fina

Como se vê pelo Gráfico 1, aumentou de maneira relevante a inclinação da curva que expressa o déficit do balanço comercial do setor a partir de 1994 e até 1999 (período em que se conviveu com câmbio muito apreciado), estabilizando-se nesse novo patamar até 2003, voltando a subir em 2004. O longo tempo de duração dessa apreciação cambial elevou substancialmente o sucateamento da indústria existente, que ocorreu após a abrupta abertura comercial realizada no início dos anos 90 . Nesse contexto, foram especialmente atingidos empreendimentos emergentes da política industrial para a química fina dos anos 80 , fato que agora está requerendo medidas especiais de política industrial, tecnológica e de comércio exterior de longo prazo, visando reativar empreendimentos produtivos e inovar tecnologias usadas no passado nessa área industrial.

\section{A nova era pós-2002}

No passado, especialmente ao longo dos anos 70/80, deu-se ênfase ao modelo de substituição de importações, mantendo-se o mercado interno fortemente protegido. Esse modelo não é mais aplicável em um país que a cada dia mais se insere no mercado externo, via acordos comerciais internacionais irreversíveis.

A nova política industrial, concebida em boa hora pelo novo governo federal em parceria com o setor privado, tem por objetivo

Tabela 1. Levantamento da situação da indústria de química fina, quanto a fechamento ou cancelamento de projetos

\begin{tabular}{lccccc}
\hline Discriminação & Intermediáriosde QF & Farmoquímicos & $\begin{array}{c}\text { Defensivos } \\
\text { Agrícolas }\end{array}$ & $\begin{array}{c}\text { Aditivos, Aromáticos } \\
\text { e Corantes }\end{array}$ \\
\hline Paralisada & 241 & 407 & 73 & 375 & 1.096 \\
Não Implementada & 208 & 110 & 10 & 27 & 355 \\
Total & 449 & 517 & 83 & 402 & 1.451 \\
\hline
\end{tabular}


implantar no País uma indústria moderna e competitiva internacionalmente, para o que se torna requerida a interação de políticas públicas visando o desenvolvimento industrial, tecnológico e de comércio exterior de forma efetiva e consistente. Nesse contexto, a nova política definiu uma série de instrumentos visando criar as condições necessárias para promover a retomada do crescimento na indústria instalada no Brasil, com ênfase na inovação tecnológica centrada nas empresas produtivas que atuam em setores estratégicos no País e com o objetivo de aumentar o saldo do balanço comercial. Os setores considerados estratégicos pela nova política são os de semicondutores, software, bens de capital, fármacos $e$ medicamentos. Os três primeiros foram selecionados em decorrência da interpenetração horizontal dos mesmos no âmbito das demais cadeias produtivas do País, e o quarto setor industrial privilegiado (fármacos e medicamentos) por sua expressão estratégicosocial e no balanço comercial externo do Brasil.

Os mecanismos para promoção do crescimento industrial deverão ser acionados por um Conselho Nacional de Desenvolvimento Industrial (CNDI), segundo a forma definida pela Lei $\mathrm{n}^{\circ} 11.080$, de $31 / 12 / 04$, que criou um órgão no qual tem assento ministros de Estado, representantes empresariais e de trabalhadores, e que tem na Agência Brasileira de Desenvolvimento Industrial (ABDI) seu braço executivo. São amplas as expectativas de uma retomada do desenvolvimento industrial nesse estratégico setor, a partir de 2005.

A indústria química brasileira como um todo, representada pelos seus segmentos industriais mais expressivos, apresenta um significado econômico que é mostrado no Gráfico 2.

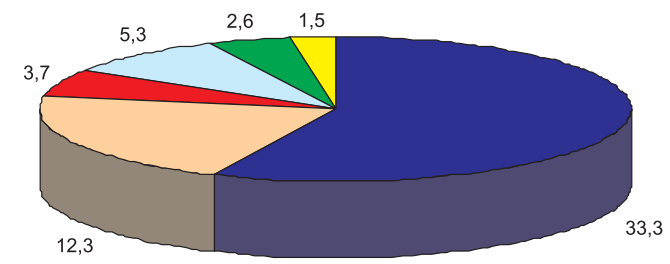

\begin{tabular}{|lll|}
\hline$\square$ prods técnicos inds & $\square$ química fina & $\square$ higiene pessoal \\
$\square$ adubos e fertilizantes & $\square$ sabões e detergetnes & $\square$ tintas e vernizes \\
\hline
\end{tabular}

Gráfico 2. Faturamento da Indústria Química Brasileira (U\$S bilhões) 2004

Esse gráfico mostra que $21 \%$ do faturamento do setor químico brasileiro (US\$12,3 em US\$58,7 bilhões) referem-se à área da química fina. $\mathrm{O}$ complexo industrial da química fina e de suas especialidades no Brasil compreende um conjunto de empresas produtivas dedicadas à fabricação de uma ampla variedade de produtos essenciais às atividades humanas, com elevado conteúdo tecnológico e valor agregado. São produtos com expressivas implicações estratégicas para o desenvolvimento autônomo do País, tais como fármacos, medicamentos, vacinas, defensivos agrícolas e animais, catalisadores industriais, corantes, aditivos e demais especialidades da química fina. A expressão econômica desse setor industrial no Brasil pode ser visualizada no Gráfico 3, em termos percentuais sobre um faturamento total hoje estimado em cerca de US $\$ 12,3$ bilhões/ano.

\section{EVOLUÇÃO DA QUÍMICA FINA NO MUNDO}

\section{Abertura de mercados}

Nos anos 40, para recuperar as abaladas economias mundiais, foram criados o Fundo Monetário Internacional (FMI), o Banco Mundial e para uma agência especial da ONU ("International Trade

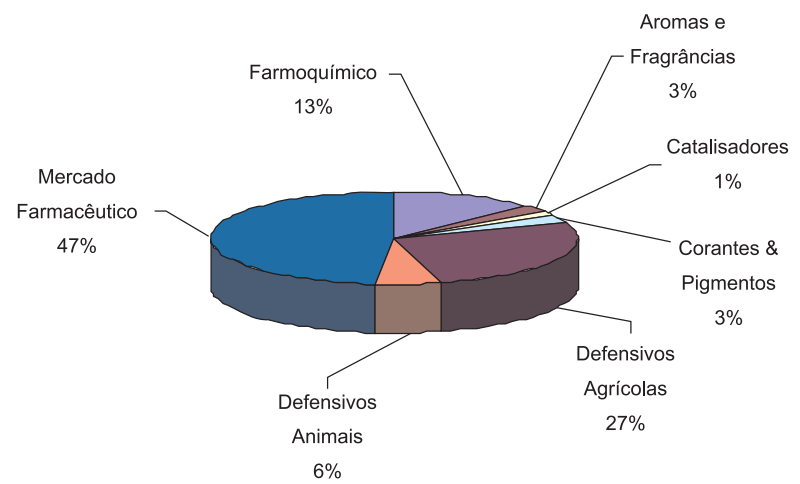

Gráfico 3. Distribuição de mercado. NOTA: dados consolidados a partir de entidades empresariais

Organization”), foi atribuída a missão de disciplinar o comércio internacional, em seus vários aspectos. Devido à abrangência da agenda prevista para a organização, sua montagem inicial foi embaralhada por inúmeros problemas, dando ensejo, em 1948, a criação de um acordo comercial provisório, denominado "General Agreement on Tariffs and Trade" (GATT), dedicado apenas à redução das tarifas aduaneiras. O acordo definitivo, devido às dificuldades para aprovação em parlamentos nacionais, somente foi alcançado após sucessivas rodadas de negociações internacionais havidas ao longo de mais de 40 anos. A negociação final ocorreu na Rodada do Uruguai, iniciada em 1986 e concluída em abril de 1994, na cidade de Marrakesh, Marrocos, ocasião em que foi fundada a Organização Mundial do Comércio (OMC).

A OMC iniciou suas atividades em 1 de janeiro de 1995, como órgão gestor do GATT e de mais 16 acordos nas seguintes áreas: agricultura, medidas sanitárias e fitossanitárias, reforma em países menos desenvolvidos, têxteis e vestuário, barreiras técnicas, investimentos, anti-dumping, valoração aduaneira, inspeção pé-embarque, regras de origem, procedimentos para licenciamento de importações, subsídios e direitos compensatórios, salvaguardas, serviços, propriedade intelectual e solução de controvérsias. Tais acordos apresentam diferentes datas de aplicação em até dez anos (períodos "de graça"), alguns dos quais já prorrogados - como o acordo da agricultura, outros em processo de rediscussão - como o de propriedade intelectual, dentro do escopo das novas negociações que hoje a OMC denomina Rodada de Doha.

O Brasil antecipou-se às obrigações constantes desses acordos, visto que abriu unilateralmente sua economia no início dos anos 90 - fazendo concessões de mercado sem quaisquer compensações negociadas com parceiros externos, perdendo, assim, excepcional moeda de troca em negociações de comércio internacional. Hoje a abertura comercial constitui processo irreversível, que exigiu um repentino aumento da produtividade da economia nacional, com a conseqüente e inevitável elevação do desemprego no País.

Competitividade internacional constitui o grande requisito para a manutenção ou a criação de qualquer novo empreendimento produtivo instalado em qualquer país no mundo.

\section{Consequiências da globalização}

Como conseqüência imediata dessa abertura econômica em nível internacional iniciou-se um processo de fusões entre empresas produtivas, visando ganhar escala e maior presença nos mercados globais, bem como seu redirecionamento estratégico com o objetivo de ser alcançada uma maior concentração no "core business" de suas respectivas atividades. 
Esse duplo megaobjetivo deu origem a um novo sistema produtivo caracterizado pelo atendimento ao mercado final crescentemente concentrado em reduzido número de grandes empresas, que são supridas por um elevado número de empresas satélites, de porte bem menor.

Tais arranjos produtivos vêm sendo influenciados, outrossim, pelas novas regras ditadas pelo acordo TRIPs -("Trade Related Intellectual Properties Rights"), componente dos acordos assinados juntamente com o GATT, em 1994, para valerem desde o início de 1995 e que, na maioria dos casos, estarão em plena vigência a partir de 31/12/2005 - ou seja, dez anos após a plena vigência dos acordos componentes do GATT. Na forma desse acordo, a não observância dos direitos de propriedade intelectual enseja retaliações econômicas no comércio internacional de bens e serviços.

Nesse contexto as grandes empresas que atuam no atendimento ao mercado consumidor final, no complexo industrial da química fina, procuram restringir o acesso nesse mercado a outros postulantes, o que é atingido em grande medida através do sistema de patentes industriais - patentes de processos e de produtos, inclusive de aplicações de tais produtos.

Deve ser lembrada a situação da Índia e da China, grandes exportadores de produtos da química fina para o Brasil. A partir de janeiro de 2005, fica encerrado o "período de graça" por eles gozado no âmbito de TRIPs e, assim, a partir dessa data serão obrigados a respeitar patentes industriais como qualquer país, desenvolvido ou não, o faz.

\section{Terceirização}

A terceirização de atividades dedicadas à fabricação de componentes de uma determinada peça ou produto constitui hoje uma realidade que deverá prevalecer por muito tempo no conserto das nações, especialmente enquanto "cláusulas trabalhistas" não fizerem parte dos acordos internacionais que tratam do comércio. Nesse contexto, a ilustração mais conhecida é a fabricação de componentes eletrônicos no Leste Asiático, cujos custos de mão-de-obra e produtividade constituem fatores de produção que não encontram paralelo em qualquer outro país do Ocidente.

$\mathrm{Na}$ área química, embora esse fato também seja expressivamente verificado nos dias atuais, outras questões deverão intervir no futuro da atividade terceirizada nesses países, em especial requisitos sanitários, ambientais e de segurança, como se apresentará nos próximos tópicos.

\section{Barreiras técnicas}

A crescente preocupação com o meio ambiente, que levou a quase totalidade dos países do mundo a assinarem o Protocolo de Kioto - com a triste exceção dos Estados Unidos de Bush, certamente deverá ter repercussões na agenda internacional. Assim, já estão sendo examinadas no ambiente do comércio multilateral novas modalidades de barreiras técnicas contra aqueles países que agridem o meio ambiente, sem qualquer controle ou sem a aplicação de programas destinados ao uso sustentado, como se verifica especialmente na China e na Índia.

Requisitos sanitários para comércio de produtos destinados ao consumo humano, por via direta ou indireta - o que inclui intermediários químicos usados na produção de alimentos, medicamentos e defensivos vegetais ou animais, já são usualmente aplicados pelos países desenvolvidos e, de forma crescente, também pelos países em desenvolvimento que são parceiros desse mesmo mercado global. Nesse contexto cabe ser destacada a recente regulamenta- ção emitida pela União Européia, denominado Regulamento para Registro, Avaliação e Autorização de Produtos Químicos (REACH), decorrente do chamado "Livro Branco" - marco regulatório que, ao introduzir o "Princípio da Precaução", já claramente constitui uma barreira técnica às importações oriundas de outros países. A própria menção no "Livro Branco" de que os países em desenvolvimento apresentam falhas em legislação, capacidade administrativa e infra-estrutura para utilização segura de produtos químicos indica claramente que a UE está disposta a se valer desse "argumento técnico" para impor aos países exportadores um enorme arsenal de barreiras técnicas, com interpretações extremamente subjetivas.

Por último, mas não menos importante, deve-se considerar os sistemas de controle de armas químicas, nucleares e bacteriológicas - inclusive seus precursores, que cada vez são mais rígidos e impositivos. Em 28/04/2004, o Conselho de Segurança da ONU adotou a Resolução 1540 estabelecendo que todos os países devem sancionar medidas para evitar a comercialização ou o desenvolvimento de armas nucleares, químicas ou biológicas, inclusive seus precursores, com o objetivo de evitar a proliferação das armas químicas, biológicas ou nucleares em geral. Nesse cenário os Estados Unidos aprovaram, recentemente, uma Lei do Bioterrorismo, que pode ser bem entendida como princípio, mas deixa a grande dúvida sobre sua utilização prática. Serão estabelecidos critérios claros, tecnicamente aceitáveis, que não permitam a criação de restrições indevidas às exportações para os Estados Unidos?

Nesse contexto, o comércio internacional de produtos químicos vem sendo sujeito a crescentes barreiras técnicas, fato que sinaliza para a necessidade de se procurar formas autônomas visando o abastecimento interno, sob pena de desabastecimento e perda de soberania em estratégicas áreas produtivas.

\section{A biotecnologia}

O Brasil atinge sua auto-suficiência na produção de combustíveis de origem fóssil justamente no momento em que mais se questiona a perenidade dessa forma de energia no mundo e, muito especialmente, de matérias-primas para a indústria petroquímica.

Coincidentemente, no entanto, as fontes alternativas de energia e de matérias-primas à rota industrial da petroquímica, que vêm sendo postas em discussão atualmente, são justamente aquelas abundantemente encontradas no Brasil: energia eólica e solar, e a biomassa.

Analisando-se comparativamente os países que contam com as maiores reservas de biodiversidade no planeta (especialmente China, Índia e Brasil), o Brasil desponta como aquele que oferece a relação mais favorável da população para a biomassa local. Noutras palavras, como o Brasil tem, para uma área equivalente, uma população a ser alimentada cerca de cinco vezes menor, muito maiores serão suas disponibilidades para utilização da biomassa como fonte de matéria-prima para a indústria.

Nesse cenário surge a biotecnologia como a grande rota para aproveitamento da biodiversidade brasileira, seja em termos energéticos (como álcool e biodiesel), seja como matéria-prima para toda a indústria química no futuro. Grandes conglomerados químicos europeus (em especial a indústria química alemã), antevendo o futuro promissor de países que, como o Brasil, nessa área já assumem o controle de algumas unidades produtivas básicas instaladas no país (usinas de álcool), bem como desenvolvem fantásticos programas de pesquisa e desenvolvimento de processos biotecnológicos, têm como objetivo transferir grande parte de seus ativos imobilizados na área química para estes países. 


\section{UM MUNDO GLOBALIZADO}

\section{Competitividade}

Produtividade e qualidade são os requisitos básicos, indispensáveis, para qualquer nova produção almejar ter sucesso, em um mundo irreversivelmente globalizado. A palavra-chave desse novo mundo é competitividade.

Substituir importações, diversificar produções, criar novas aplicações para produtos conhecidos, tudo isso faz sentido desde que haja competitividade da produção local com similares fabricados em outros países.

Programas de qualidade e produtividade, destinados a conferir competitividade a qualquer empresa, devem ser permanentemente adotados por todas as indústrias. A competitividade deve estar aliada ao nível de satisfação do consumidor final.

\section{Capacitação técnica}

Em um mundo globalizado, para se competir no mercado há que se possuir excelentes quadros técnicos, plenamente capacitados não somente a conduzir processos de fabricação de produtos. Requer-se uma eficiente competência técnica, também, para a defesa da empresa contra práticas desleais de concorrentes, bem como para vencer barreiras técnicas que são comumente apresentadas em mercados externos. No passado, o engenheiro químico, o químico e o farmacêutico eram vistos como técnicos de projetos de engenharia de processos químicos ou farmacêuticos, ou de pesquisa e análise; hoje o campo profissional para os químicos e farmacêuticos, em termos de números de pessoas absorvidas, está muito mais direcionado às aplicações de produtos em um mercado extremamente competitivo e com o comércio regulado do que nos processos de fabricação. Os mercados nacional e internacional apresentam oportunidades e inibições em matéria técnica, especialmente via regulamentos sanitários, propriedade intelectual e controles ao comércio de drogas químicas. Nesse contexto, os profissionais também devem estar devidamente preparados para enfrentar enormes dificuldades e grandes barreiras técnicas em matéria correlata à sua formação profissional, como detalhadas a seguir:

\section{Propriedade intelectual}

O acordo TRIPs (“Trade Related Intelectual Property Rights”), um dos componentes do GATT, subscrito pelo Brasil em 1994, resultou em diversas leis brasileiras, com destaque para a lei de patentes (Lei n ${ }^{\circ}$ 9.279, de 14/05/96). Nesse âmbito, cuidados imensos devem ser tomados na fabricação e comercialização de produtos, visto que a leitura e a interpretação de patentes industriais constituem tarefas especializadas, que requerem conhecimento e treinamento específico nessa matéria; há uma inversão do ônus da prova, ou seja, baseada em uma acusação de concorrente, uma fábrica poderá ser fechada por determinação de um Juiz de primeira instância, a menos que o acusado comprove não estar burlando a lei; as infrações a essa lei são consideradas crimes de concorrência desleal - o que submete os dirigentes empresariais a duras penalizações de caráter pessoal pelo não cumprimento de seus dispositivos.

\section{Registro sanitário e fitossanitário de produtos}

No Brasil, a Agência Nacional de Vigilância Sanitária (ANVISA) estabelece normas e procedimentos para registro de produtos destinados ao uso humano, como pré-requisitos à comercialização de tais produtos. Todos os países avançados dispõem de legislações nacionais nessa área, que são fiscalizadas por órgãos dos respectivos governos locais, como "Food and Drug Administration (FDA)", dos Estados Unidos. Ocorre que, mais recentemente, tem surgido novas legislações nessa matéria, de caráter regional ou nacional que, se não forem devidamente acompanhadas, poderão se transformar em barreiras técnicas ao ingresso de produtos externos em tais áreas. Nesse contexto podem ser lembradas: a União Européia definiu um Regulamento para Registro, Avaliação e Autorização de Produtos Químicos (REACH), marco regulatório que constitui uma potencial barreira técnica às importações oriundas de outros países, dado seu caráter extremamente subjetivo para decisões nesse cenário; a Lei do Bioterrorismo, promulgada pelos Estados Unidos em 2002, estabelece exigências para "drogas e dispositivos" usados em alimentos, o que irá criar enormes dificuldades para os fornecedores de outros países, inclusive decorrente da imposição de elevados custos para registro de produtos nessa área, que poderão tornar proibitivas as exportações dos países latino-americanos para os Estados Unidos; decisões tópicas, como recentes impasses do Brasil com a Rússia e a Argentina, ocasiões em que houve um excessivo rigor de parte daqueles países, ao suspenderem compras de carne alegando a existência de febre aftosa no Brasil, mesmo sendo público e notório que tal situação se limitava a uma pequena área do país, sob absoluto controle do governo federal.

\section{Meio ambiente}

Ressalvado o caráter absolutamente procedente de medidas que objetivem a tecnicamente correta defesa do meio ambiente, não se pode confundir tais procedimentos com a aplicação de instrumentos preconceituosos, de natureza puramente ideológica ou fundamentalista, que inibem pesadamente o crescimento sustentado da biodiversidade brasileira. Também aqui há grande necessidade de um aprofundado conhecimento dessa matéria, para que o exercício profissional possa ser conduzido de forma correta.

\section{Políticas regionais}

A assimetria estrutural entre países, bem como entre regiões de um mesmo país, requer a adoção de políticas públicas que visem o desenvolvimento regional, no contexto de regras plenamente aceitas pela OMC. Nessa área o Brasil já vem exercendo há muitos anos sua soberania, em especial nas regiões norte, nordeste e centro/oeste, com expressivo sucesso. O pleno conhecimento de tais políticas é de fundamental importância quando se analisam alternativas para a localização de novos empreendimentos.

\section{PERSPECTIVAS PARA O BRASIL}

\section{Políticas públicas}

Vencer o "gap" tecnológico que afasta o Brasil dos países de Primeiro Mundo somente poderá ser alcançado através do uso de uma política industrial efetiva, tecnológica e de comércio exterior (PITCE), balizada nos princípios definidos pelo Governo Federal no dia 31/03/2004, por ocasião do lançamento dessa nova política pública.

Nesse contexto de novas políticas públicas, cabe destacar os seguintes instrumentos:

- Uso do poder de compra do Estado, mecanismo da maior importância destinado a fomentar a fabricação, no País, dos medicamentos e fármacos requeridos para atender os sistemas de saúde pública, através de critérios de qualidade (exigência de inspeção e certificação pela Agência de Vigilância Sanitária), 
isonomia no tratamento tributário, preferência nas compras de produtos com maior valor e conteúdo tecnológico agregados localmente e, contratação de compras para o fornecimento no longo prazo.

- Lei da Inovação, matéria que foi aprovada recentemente (Lei $\mathrm{n}^{\circ} 10.973$, de 02/12/04), mas que ainda requer regulamentação adequada, em especial da subvenção econômica (art. 19) e aprovação de um projeto de lei sobre incentivos fiscais, previstos no artigo 28. Pretende-se que o uso de incentivos fiscais para atividades de P\&D\&I seja feito de forma ágil e desburocratizada, sem haver a necessidade de prévia aprovação de projeto em agências oficias, embora o sujeitando à rigorosa e detalhada comprovação a posteriori, junto aos órgãos arrecadadores.

- Financiamento para $P \& D \& I$ em condições similares ao que ocorre no Primeiro Mundo, recursos orçamentários de longo prazo assegurados (sem contingenciamento) e em condições adequadas aos investimentos com risco tecnológico (garantias, prazos, parceria no risco e taxas de juros reduzidas).

- Programas especiais para biotecnologia e nanotecnologia, visando a identificação dos atores indispensáveis- empresa e centro de $\mathrm{P} \& \mathrm{D}$, requeridos para a sustentação da indústria de fármacos e medicamentos (definida como uma das quatro prioridades da nova política industrial) no longo prazo. Para tanto, é necessário que seja iniciado, desde já, um programa de capacitação das empresas em tecnologias de ponta, como a biotecnologia e a nanotecnologia, por serem processos indispensáveis para atender aos requisitos da moderna farmacologia humana e para a defesa vegetal ou animal. A nova política industrial destaca-as como sendo as tecnologias portadoras de futuro, mas iniciativas nessa área devem ser adotadas desde logo.

\section{Verticalização da cadeia produtiva}

Diferentemente do que ocorre nos demais setores priorizados pela nova política industrial (semicondutores, software, bens de capital), cujos efeitos permeiam horizontalmente toda a estrutura produtiva, o setor de fármacos e medicamentos constitui um setor industrial concebido de forma verticalmente integrada e, assim, requer um tratamento distinto daqueles setores.

A viabilização da política industrial para a área farmacêutica passa, necessariamente, pela fabricação local de princípios ativos ou matérias-primas para esse segmento da cadeia produtiva de medicamentos, sendo conveniente o exame das possibilidades de se buscar a especialização de empresas em processos produtivos (em vez de produtos), localizadas a montante da referida cadeia produtiva.

No atual cenário da globalização econômica, o desenvolvimento de uma cadeia produtiva verticalizada como a de fármacos e medicamentos, somente será viável ao longo prazo, no Brasil, se levar em conta tanto seu mercado (medicamentos) quanto sua base química necessária, formada pelos insumos requeridos pela indústria - intermediários de síntese. A origem de tais insumos poderá ser encontrada, inclusive, a médio e longo prazo nos abundantes recursos da biodiversidade brasileira, fato que em si mesmo já constitui enorme vantagem comparativa do Brasil em relação ao exterior. Além disso, para tornar economicamente viável tal empreendimento, sua base industrial química deverá ser dimensionada para atender, também, a outros mercados da química fina, no Brasil e no exterior.

Este fato relevante requer não só o apoio do Estado para uma contínua inovação tecnológica e estimular os novos investimentos nas empresas nacionais instaladas no País como, também, necessi- ta da efetiva participação do Estado, em parceria com o setor produtivo interno, para a montagem dessa sólida indústria química de intermediários, a ser implantada com escala produtiva adequada para permitir que as matérias-primas estratégicas requeridas pelo setor apresentem qualidade e preços competitivos internacionalmente, do que resultará que, também, possam ser exportadas.

Assim sendo, para viabilização da atual política industrial, tecnológica e de comércio exterior para o setor de medicamentos e fármacos, em especial para ser competitiva internacionalmente no longo prazo, deve ser buscada, desde logo, a implantação de uma indústria química orgânica destinada a fabricar as matérias-primas requeridas para os diversos segmentos da química fina nacional, com porte suficiente para também acessar mercados externos. Essa iniciativa deveria levar em conta o estudo "Projeto Estruturante para a Indústria de Química Fina no Brasil”, realizado pela Escola de Química da UFRJ, sob a coordenação da Profa. Adelaide Antunes e que, partindo da análise estatística das importações de produtos químicos estratégicos para a economia brasileira, verificadas no decênio dos anos 90 (valores superiores a US\$10 milhões/ano), identificou os processos químicos unitários e os insumos requeridos para a fabricação de tais produtos: nitração, esterificação, ciclização, redução, amidação, diazotação, cloração, alcoilação, condensação, fosforilação, oxidação, hidrogenação e fermentação.

Um projeto dessa magnitude, e com tal significado estratégico para o crescimento soberano do País, certamente irá requerer uma presença bem mais expressiva do Estado brasileiro, seja através de seu braço promotor do desenvolvimento (BNDESPAR), seja através da empresa estatal que liderou exemplarmente a implantação da indústria petroquímica no Brasil nos anos 70 (PETROBRAS). Um projeto desse porte poderia ser concebido hoje, no Brasil, a partir do projeto da PETRORIO, empresa ligada à PETROBRAS e que está estudando a implantação de uma refinaria petroquímica no Estado do Rio de Janeiro, a partir do petróleo pesado de Campos, em parceria com empresas químicas atuantes no setor.

Obviamente um projeto dessa natureza requer a realização de um profundo e consistente estudo de viabilidade técnico-econômica.

\section{CONSIDERAÇÕES FINAIS}

Do cenário apresentado neste trabalho, podem ser destacados os seguintes conceitos que consideramos da maior relevância para os objetivos perseguidos:

- Em um mercado globalizado, e de forma irreversível, a competitividade internacional de produtos fabricados localmente constitui uma necessidade insuperável para a sobrevivência e o crescimento, a razão do sucesso para a manutenção da empresa produtiva e para o lançamento de novos produtos.

- Em decorrência desse enfoque fundamental, o mercado é que dita para quais produtos, e com quais características, ocorre a demanda. Assim sendo, o mercado é que condiciona a tecnologia a ser usada, a qual vai ser alimentada pelos conhecimentos científicos requeridos para a evolução tecnológica que se fizer necessária. Inversamente ao pensamento linear extremamente difundido de que a inovação tecnológica começa na pesquisa acadêmica, posteriormente dando origem à tecnologia para fabricar o produto que o mercado deve, automaticamente, absorver.

- Quando uma indústria vende um produto, ela está colocando no mercado mais do que uma simples mercadoria: está disponibilizando um serviço de assistência técnica a um consumidor cada vez mais exigente.

- Os compromissos legais do fabricante não se restringem à colocação do produto no mercado, em uma simples ação de venda. Os efeitos decorrentes da aplicação desse produto pelo consu- 
midor, não somente devem satisfazê-lo para continuar seu suprimento como, em caso de falhas ou prejuízos, os danos daí decorrentes podem expressivamente recair sobre o produtor, mesmo que isso ocorra muitos anos após a data da sua fabricação.

- Por tudo isso, as políticas públicas são focadas cada vez mais na empresa produtiva e, conseqüentemente, maior é o envolvimento da indústria nas tarefas atinentes à inovação tecnológica, e maior é a responsabilidade do empresário com as consequiências da aplicação dos produtos pelo consumidor.

- A capacitação técnica de uma empresa, sem prejuízo da qualidade de seus produtos e da eficiência de seus processos, deixa de ser focada, essencialmente, nos processos operacionais que pratica para ser muito mais atenta ao mercado que os demanda, em especial para toda uma regulamentação crescente e sofisticada, que se altera diuturnamente em nível internacional.

- Nesse contexto o planejamento estratégico de uma empresa, para atuar em um mercado extremamente competitivo e mutante, passa a requerer o apoio de competências técnicas cada vez maiores e mais diversificadas, diretamente vinculadas aos maiores níveis da gestão empresarial.
- A articulação empresarial através de entidades de classe, com o objetivo de sensibilizar os poderes de República para a defesa do mercado interno - patrimônio nacional definido pela Constituição Federal, é uma tarefa que as empresas nacionais não poderão abdicar jamais, sob pena de serem expelidas desse mercado global extremamente competitivo, que se vale dos mais variados instrumentos para sua sobrevivência.

- Nesse contexto destaca-se que a parceria do setor privado com o Governo, em ambiente de seriedade e cooperação interna visando o desenvolvimento nacional, constitui tarefa absolutamente indispensável.

- O Governo Federal não pode se expressar de formas distintas, muitas as vezes conflitantes, pelos diferentes órgãos que o compõe. As ações do governo federal, nas áreas de política industrial, tecnológica e de comércio exterior, devem expressar um Projeto de Estado Nacional, com caráter plurianual e, fundamentalmente, ser bem articulado institucionalmente em seus vários ministérios. Isso constitui uma receita imprescindível para o sucesso das políticas públicas nessa área e à própria sustentação de empresas nacionais no mercado globalizado. 